\title{
Inverse associations of outdoor activity and vitamin D intake with the risk of Parkinson's disease
}

\author{
Dan ZHU ${ }^{1}$, Gui-you LIU ${ }^{2}$, Zheng LV $^{3}$, Shi-rong $\mathrm{WEN}^{4}$, Sheng $\mathrm{BI}^{4}$, Wei-zhi WANG ${ }^{\dagger+1}$ \\ ( ${ }^{1}$ Department of Neurology, the Second Affiliated Hospital, Harbin Medical University, Harbin 150086, China) \\ $\left({ }^{2}\right.$ Genome Analysis Laboratory, Tianjin Institute of Industrial Biotechnology, Chinese Academy of Sciences, Tianjin 300308, China) \\ $\left({ }^{3}\right.$ Department of Rehabilitation, the First Affiliated Hospital, Harbin Medical University, Harbin 150001, China) \\ $\left({ }^{4}\right.$ Department of Neurology, the First Affiliated Hospital, Harbin Medical University, Harbin 150001, China) \\ †E-mail: dwangwz@163.com
}

Received Jan. 3, 2014; Revision accepted June 11, 2014; Crosschecked July 25, 2014

\begin{abstract}
Early studies had suggested that vitamin D intake was inversely associated with neurodegenerative diseases, such as Alzheimer's disease and multiple sclerosis. However, the associations of vitamin D intake and outdoor activities with Parkinson's disease (PD) are still unclear, so this study is to evaluate these relationships from a case-control study in elderly Chinese. The study population involved 209 cases with new onsets of PD and 210 controls without neurodegenerative diseases. The data on dietary vitamin $D$ and outdoor activities were collected using a food-frequency questionnaire and self-report questionnaire. Multivariable logistic regressions were used to examine the associations between dietary outdoor activities, vitamin D intake and PD. Adjustment was made for sex, age, smoking, alcohol use, education, and body mass index (BMI). Adjusted odds ratios (ORs) for PD in quartiles for outdoor physical activity were 1 (reference), $0.739(0.413,1.321), 0.501(0.282,0.891)$, and $0.437(0.241,0.795)$, respectively ( $P=0.002$ for trend). Adjusted ORs for PD in quartiles for total vitamin $\mathrm{D}$ intake were 1 (reference), 0.647 $(0.357,1.170), 0.571(0.318,1.022)$, and $0.538(0.301,0.960)$, respectively $(P=0.011$ for trend). Our study suggested that outdoor activity and total vitamin $D$ intake were inversely associated with PD, and outdoor activity seems to be more significantly associated with decreased risk for PD.
\end{abstract}

Key words: Outdoor activity, Vitamin D intake, Parkinson's disease doi: $10.1631 /$ jzus.B1400005

Document code: A

CLC number: R741

\section{Introduction}

Parkinson's disease (PD) is a common progressive neurodegenerative disorder, causing disability in the elderly (Voelker, 2006; Sehanovic et al., 2011). Although the pathogenesis remains elusive, environmental factors for PD have been proposed to be connected with the origin of this disease (Lees et al., 2009; Liu et al., 2011). Specific nutrients and food intake habits have been investigated as potential risk factors or protectors for PD (Anderson et al., 1999;

\footnotetext{
${ }^{\ddagger}$ Corresponding author

(C) Zhejiang University and Springer-Verlag Berlin Heidelberg 2014
}

Ross et al., 2000; Park et al., 2005; Gao et al., 2007; Jiang et al., 2014).

Vitamin D plays an important role in the pathogenesis of chronic diseases (e.g., cancer, cardiovascular diseases, and diabetes) and some progressive neurodegenerative disorders (such as Alzheimer's disease and multiple sclerosis) (Knekt et al., 2010; Annweiler et al., 2013). Recently, chronically inadequate vitamin $\mathrm{D}$ was proposed to play a significant role in the pathogenesis of PD (van den Bos et al., 2013). According to the suggested biological mechanism, the PD may be caused by a continuously inadequate vitamin D status, leading to a chronic loss of dopaminergic neurons in the brain (Knekt et al., 
2010). However, this finding was not reported for the Chinese population.

Outdoor activities were also reported to be linked to PD (Kenborg et al., 2011). Additionally, the dynamic changes of serum vitamin D are determined by dietary and sun avoidance factors, as $20 \%$ vitamin $\mathrm{D}$ is obtained from food (eggs, fish, animal liver, and dairy products), while $80 \%$ is from skin synthesis as a product of skin 7-dehydrocholesterol transformations induced by ultraviolet radiation (American Diabetes Association, 2007; Marcinowska-Suchowierska et al. 2010). Therefore, besides the benefit of outdoor activity per se, outdoor activity could also influence vitamin D status. These two factors should be both considered in one study; however, the epidemiological study on the relationships between intake of vitamin D, outdoor activities and the risk of PD was still limited.

In this study, we evaluated the relationships between intake of vitamin $\mathrm{D}$, outdoor activities and the risk of PD using data from a relatively large-scale case-control study in a Chinese population.

\section{Materials and methods}

Two hundred and nine PD cases with new onsets and 210 age and sex matched healthy controls were included in this study at a clinic in the First and Second Affiliated Hospitals of Harbin Medical University and three community hospitals between Nov. 1, 2012 and Mar. 1, 2013 in Harbin in northern China. PD was diagnosed by the neurologists according to the UK PD Society Brain Bank clinical diagnostic criteria. Inclusion criteria were a new onset of PD and no other neurodegenerative diseases. The study protocol was approved by the Ethics Committee of the Harbin Medical University. Each participant was informed about the study and signed a consent form. All participants completed a questionnaire-based interview and received a physical examination. Investigators were trained in administering the questionnaire and physical examination before the survey.

Data of each patient on educational status, outdoor physical activity (hours per week), smoking and drinking status, and medical history were collected using a face-to-face questionnaire answered by the participants. Dietary intakes were measured with a validated semi-quantitative food-frequency questionnaire (FFQ) (Li et al., 2010). Dietary vitamin D intakes were calculated using the Food Nutrition Calculator (V1.60; the Centers for Disease Control of China). A questionnaire on the use of vitamin D as a supplement was administered. The information on using vitamin D supplements included the time and dosage of the supplements. Total vitamin D was calculated as dietary plus supplemented vitamin D. Weight and height were measured to the nearest $0.1 \mathrm{~kg}$ and $0.1 \mathrm{~cm}$, respectively. Blood pressure was measured with a standard mercury sphygmomanometer. Body mass index (BMI) was calculated as weight $(\mathrm{kg})$ divided by the square of height (m).

Data were presented as mean \pm standard deviation (SD) or percentages as appropriate. Outdoor physical activity and total dietary vitamin D intake were categorized at quartile points, respectively. Multivariable logistic regression models were developed to evaluate the associations between dietary vitamin D, outdoor activity and PD after adjustment for age, sex, education, BMI, alcohol use, and smoking. Estimations of odds ratios (ORs) and their 95\% confidence intervals (CIs) of PD for each category of the total vitamin D intake in comparison with the lowest category were assessed. The significance level was set at $P<0.05$ and tests were two-tailed for all statistical analyses in this study.

\section{Results and discussion}

There were no significant differences between the case and control groups in age, sex, education, percentage of current smoking, alcohol use, or indoor activity (Table 1). Compared with control subjects, PD cases had a significant higher BMI and lower total vitamin D intakes and outdoor physical activity hours. For outdoor physical activity, all the subjects claimed to walk and perform slow aerobic exercise. Table 2 presents crude and adjusted ORs and 95\% CIs for the risk of PD associated with outdoor physical activity, which was grouped in quartiles: 1, 0-2 h/week; 2, 2-4 h/week; 3, 4-6 h/week; and 4, >6 h/week. In the crude analysis, the inverse associations between the outdoor physical activity in the third and fourth quartiles and $\mathrm{PD}$ were significant ( $P=0.001$ for trend). After adjustment for age, sex, alcohol use, smoking, 
education, BMI, and total vitamin D intake, the adjusted ORs for PD in quartiles for outdoor physical activity were 1 (reference), $0.739(0.413,1.321)$, $0.501(0.282,0.891)$, and $0.437(0.241,0.795)$, respectively ( $P=0.002$ for trend). For total vitamin $\mathrm{D}$ intake in this crude analysis, inverse association was observed between total vitamin $\mathrm{D}$ intake and the risk of PD. Total vitamin $\mathrm{D}$ intake was categorized in quartiles: $1,0-5 \mu \mathrm{g} / \mathrm{d} ; 2,5-8 \mu \mathrm{g} / \mathrm{d} ; 3,8-12 \mu \mathrm{g} / \mathrm{d}$; and 4 , $>12 \mu \mathrm{g} / \mathrm{d}$. A negative association between vitamin D intake and PD was observed only at the top quartile. When adjusted for age, sex, alcohol use, smoking,

Table 1 Characteristics of the participants in this study

\begin{tabular}{|c|c|c|c|}
\hline Parameter & $\begin{array}{c}\text { Case } \\
(n=209)\end{array}$ & $\begin{array}{l}\text { Control } \\
(n=210)\end{array}$ & $P$ \\
\hline Age (year) & $64.6 \pm 9.4$ & $66.0 \pm 8.1$ & 0.10 \\
\hline Male/female & $73 / 136$ & $76 / 134$ & 0.84 \\
\hline Current smoking & $50(23.9 \%)$ & $54(25.7 \%)$ & 0.74 \\
\hline Alcohol use & $50(23.9 \%)$ & $60(28.6 \%)$ & 0.32 \\
\hline \multicolumn{4}{|l|}{ Education } \\
\hline$<9$ years & $87(41.6 \%)$ & $83(39.5 \%)$ & 0.35 \\
\hline $9-12$ years & $74(35.4 \%)$ & $66(31.4 \%)$ & \\
\hline$>12$ years & $48(23.0 \%)$ & $61(29.0 \%)$ & \\
\hline BMI $\left(\mathrm{kg} / \mathrm{m}^{2}\right)$ & $24.8 \pm 2.5$ & $23.9 \pm 2.1$ & $<0.01$ \\
\hline $\begin{array}{l}\text { Outdoor activity } \\
\text { (h/week) }\end{array}$ & $3.9 \pm 3.1$ & $5.0 \pm 3.5$ & 0.001 \\
\hline $\begin{array}{l}\text { Indoor activity } \\
\text { (h/week) }\end{array}$ & $13.2 \pm 1.2$ & $12.9 \pm 1.9$ & 0.10 \\
\hline $\begin{array}{l}\text { Vitamin D intake } \\
(\mathrm{g} / \mathrm{d})\end{array}$ & $8.4 \pm 4.3$ & $9.6 \pm 4.7$ & 0.005 \\
\hline
\end{tabular}

Data are expressed as mean \pm SD or number of subjects (percentage). Differences between cases and controls were assessed using a $t$-test for continuous data and $\chi^{2}$ test for binary data education, BMI, and outdoor physical activity, adjusted ORs for PD in the quartiles for total vitamin D intake were 1 (reference), $0.647(0.357,1.170), 0.571$ $(0.318,1.022)$, and $0.538(0.301,0.960)$, respectively ( $P=0.011$ for trend). As outdoor physical activity and total vitamin D intake were included in the same model of multiple logistics, it seems that outdoor physical activity was more strongly associated with a lower risk for PD. To investigate whether there is a joint effect of vitamin $\mathrm{D}$ and physical activity on the risk for PD, we analyzed these variables in the same model, but did not find a significant effect of vitamin $D \times$ physical activity ( $P=0.606$; Table 3$)$. This finding indicated that both vitamin $\mathrm{D}$ and physical activity might have independent effects on PD.

As for the outdoor activity, Kenborg et al. (2011) recently reported that men working outdoors have a lower risk of PD, which is in line with our results. The mechanism of this finding was still unclear. However, the recent study has indicated that greater intensity of physical activity was associated with a shorter time to complete the trail-making test and higher levels of verbal fluency, and positively correlated with brain volume, white matter, as well as a parietal lobe gray matter volume situated bilaterally at the precuneus in the older human (Xu et al., 2010; Speelman et al., 2011; Abrantes et al., 2012). Moreover, improved vitamin $\mathrm{D}$ status through sunlight during outdoor physical activity could be another potential factor for its protective role in development of PD. As serum vitamin $\mathrm{D}$ is related to dietary and sun avoidance (Marcinowska-Suchowierska et al., 2010), outdoor activity might have multiple roles in the protection of PD.

Table 2 ORs and 95\% CIs for Parkinson's disease in quartiles for outdoor physical activity and vitamin D intake in the same model

\begin{tabular}{|c|c|c|c|c|c|c|c|c|}
\hline \multirow[b]{2}{*}{ Quartile } & \multicolumn{4}{|c|}{ Outdoor activity } & \multicolumn{4}{|c|}{ Total vitamin D intake } \\
\hline & $\begin{array}{c}\text { Time } \\
\text { (h/week) }\end{array}$ & $n_{\text {case }} / n_{\text {control }}$ & $\begin{array}{c}\text { Crude OR } \\
(95 \% \text { CI })\end{array}$ & $\begin{array}{c}\text { Adjusted OR } \\
(95 \% \mathrm{CI})\end{array}$ & $\begin{array}{l}\text { Intake } \\
(\mu \mathrm{g} / \mathrm{d})\end{array}$ & $n_{\text {case }} / n_{\text {contro }}$ & $\begin{array}{c}\text { Crude OR } \\
(95 \% \text { CI })\end{array}$ & $\begin{array}{c}\text { Adjusted OR } \\
(95 \% \mathrm{CI})\end{array}$ \\
\hline 1 & $<2$ & $63 / 40$ & 1 & 1 & $<5$ & $62 / 44$ & 1 & 1 \\
\hline 2 & $2-4$ & $56 / 49$ & $\begin{array}{c}0.748 \\
(0.427,1.311)\end{array}$ & $\begin{array}{c}0.739 \\
(0.413,1.321)\end{array}$ & $5-8$ & $51 / 52$ & $\begin{array}{c}0.589 \\
(0.331,1.049)\end{array}$ & $\begin{array}{c}0.647 \\
(0.357,1.170)\end{array}$ \\
\hline 3 & $4-6$ & $47 / 57$ & $\begin{array}{c}0.550 \\
(0.313,0.967)\end{array}$ & $\begin{array}{c}0.501 \\
(0.282,0.891)\end{array}$ & $8-12$ & $52 / 63$ & $\begin{array}{c}0.568 \\
(0.319,1.009)\end{array}$ & $\begin{array}{c}0.571 \\
(0.318,1.022)\end{array}$ \\
\hline 4 & $>6$ & $42 / 64$ & $\begin{array}{c}0.388 \\
(0.218,0.692)\end{array}$ & $\begin{array}{c}0.437 \\
(0.241,0.795)\end{array}$ & $>12$ & $43 / 61$ & $\begin{array}{c}0.505 \\
(0.288,0.887)\end{array}$ & $\begin{array}{c}0.538 \\
(0.301,0.960)\end{array}$ \\
\hline $\begin{array}{l}P \text { for } \\
\text { trend }\end{array}$ & & & 0.001 & 0.002 & & & 0.021 & 0.011 \\
\hline
\end{tabular}

Quartile 1 as reference. $n_{\text {case }} / n_{\text {control }}$ : the number of cases to the number of controls. Adjusted OR: adjusted for sex, age, smoking, alcohol use, education, and BMI 
Table 3 ORs and 95\% CIs for Parkinson's disease by outdoor activity, vitamin D intake, and vitamin D intake× outdoor activity in the same model

\begin{tabular}{|c|c|c|c|c|c|c|c|}
\hline \multirow[b]{2}{*}{ Level } & \multicolumn{3}{|c|}{ Outdoor activity } & \multicolumn{3}{|c|}{ Total vitamin D intake } & \multirow{2}{*}{$\begin{array}{c}\text { Vitamin D intake } \times \\
\text { outdoor activity } \\
\text { OR }(95 \% \text { CI })\end{array}$} \\
\hline & $\begin{array}{c}\text { Time } \\
\text { (h/week) }\end{array}$ & $n_{\text {case }} / n_{\text {control }}$ & $\begin{array}{c}\text { Adjusted OR } \\
(95 \% \mathrm{CI})\end{array}$ & $\begin{array}{l}\text { Intake } \\
(\mu \mathrm{g} / \mathrm{d})\end{array}$ & $n_{\text {case }} / n_{\text {control }}$ & $\begin{array}{c}\text { Adjusted OR } \\
(95 \% \mathrm{CI})\end{array}$ & \\
\hline Reference & $<4$ & $119 / 89$ & 1 & $<8$ & $62 / 44$ & 1 & \\
\hline Higher level & $>4$ & $89 / 121$ & $\begin{array}{c}0.494 \\
(0.279,0.877) \\
\end{array}$ & $>8$ & $51 / 52$ & $\begin{array}{c}0.613 \\
(0.348,1.080) \\
\end{array}$ & $\begin{array}{c}1.231 \\
(0.559,2.711) \\
\end{array}$ \\
\hline$P$ for trend & & & 0.016 & & & 0.09 & 0.606 \\
\hline
\end{tabular}

In line with our findings, lower serum vitamin D was also significantly associated with an increased risk of PD, whereas supplemental intake of vitamin D was related to a lower risk of PD (Knekt et al., 2010; van den Bos et al., 2013). However, no material associations between them were found in another case-control study (Miyake et al., 2011). Considering the mild association between vitamin D intake and PD detected in our larger population, we think that a smaller sample size and unmatched controls might contribute to the insignificant association in previous studies. Larger cohort population studies with controlled confounders are needed to validate this issue.

The mechanisms of how vitamin D protects against PD are not clear. One possible explanation is that vitamin $\mathrm{D}$ exhibits neuroprotective effects, which might be due to its anti-oxidative mechanisms, neuronal calcium regulation, immunomodulation, enhanced nerve conduction, and detoxification mechanisms (Buell and Dawson-Hughes, 2008). The chronic inadequacy of vitamin D leads to the loss of dopaminergic neurons in the substantia nigra region and causes the further development of PD.

Another explanation might be the insulin resistance. Vitamin D and physical activity are both inversely associated with poor insulin resistance, and insulin resistance has been accepted as a link with PD. Individuals with vitamin $\mathrm{D}$ deficiency are at an increasing risk for dyslipidemia, insulin resistance, and type 2 diabetes (Holick, 2007). In addition, outdoor activity could also improve insulin resistance. Thus, outdoor activity and vitamin D intake might both protect $\mathrm{PD}$ through maintaining normal and stable insulin sensitivity.

Before this study, we have discussed and considered the possible confounding variables in this study. We all agreed that some important factors, such as vitamin D supplements, outdoor activity, age, BMI, smoking, drinking, education, foods rich in vitamin $\mathrm{D}$, living location, and traveling to other places, could influence the vitamin D status. Thus, we selected the three living locations (communities) with similar buildings and sun exposure time. Subjects always traveling to southern places were excluded. And the other factors were all considered (age and sex were matched between groups) and adjusted in the analysis. So we think we could gain a more confident finding regarding the confounding factors control. Additionally, this study included a relatively larger population, which would give us a more stable result and statistical power.

However, there are some limitations to be considered. First, the small number of cases and case-control study design may still lead to instable results. Second, absent measurement of serum 25-hydroxyvitamin D (25-OHD) is another limitation in this study. Although poor dietary habits and outdoor physical activity could contribute to the vitamin D deficiency/insufficiency, but the lack of data on serum 25-OHD may not fully represent the vitamin D status in this study. Thus, readers should take the results with some caution. More accurate measurements should be used in cohort studies.

In conclusion, our findings from this Chinese case-control study suggest that outdoor activity and vitamin D intake are both inversely associated with $\mathrm{PD}$, and outdoor activity seems to have a stronger association.

\section{Acknowledgements}

We sincerely thank Dr. Alek CHOO (Eastern Cereal and Oilseed Research Centre, Agriculture and Agri-Food Canada) for providing valuable barley varieties for this study.

\section{Compliance with ethics guidelines}

Dan ZHU, Gui-you LIU, Zheng LV, Shi-rong WEN, Sheng BI, and Wei-zhi WANG declare that they have no conflict of interest.

All procedures followed were in accordance with the ethical standards of the responsible committee on human experimentation (institutional and national) and with the Helsinki Declaration of 1975, as revised in 2008 (5). Informed consent was obtained from all patients for being included in the study. Additional informed consent was obtained from all patients for which identifying information is included in this article. 


\section{References}

Abrantes, A.M., Friedman, J.H., Brown, R.A., et al., 2012. Physical activity and neuropsychiatric symptoms of Parkinson disease. J. Geriatr. Psychiatry Neurol., 25(3): 138-145. [doi:10.1177/0891988712455237]

American Diabetes Association, 2007. Nutrition recommendations and interventions for diabetes: a position statement of the American diabetes association. Diabetes Care, 30(Suppl. 1):S48-S65. [doi:10.2337/dc07-S048]

Anderson, C., Checkoway, H., Franklin, G.M., et al., 1999. Dietary factors in Parkinson's disease: the role of food groups and specific foods. Mov. Disord., 14(1):21-27. [doi:10.1002/1531-8257(199901)14:1<21::AID-MDS10 06>3.3.CO;2-P]

Annweiler, C., Llewellyn, D.J., Beauchet, O., 2013. Low serum vitamin D concentrations in Alzheimer's disease: a systematic review and meta-analysis. J. Alzheimer's Dis., 33(3):659-674. [doi:10.3233/JAD-2012-121432]

Buell, J.S., Dawson-Hughes, B., 2008. Vitamin D and neurocognitive dysfunction: preventing "D"ecline? Mol. Aspects Med., 29(6):415-422. [doi:10.1016/j.mam.2008. 05.001]

Gao, X., Chen, H., Fung, T.T., et al., 2007. Prospective study of dietary pattern and risk of Parkinson disease. Am. $J$. Clin. Nutr., 86(5):1486-1494.

Holick, M.F., 2007. Vitamin D deficiency. N. Engl. J. Med., 357(3):266-281. [doi:10.1056/NEJMra070553]

Jiang, W., Ju, C., Jiang, H., et al., 2014. Dairy foods intake and risk of Parkinson's disease: a dose-response metaanalysis of prospective cohort studies. Eur. J. Epidemiol., 29(9):613-619. [doi:10.1007/s10654-014-9921-4]

Kenborg, L., Lassen, C.F., Ritz, B., et al., 2011. Outdoor work and risk for Parkinson's disease: a population-based case-control study. Occup. Environ. Med., 68(4):273-278. [doi:10.1136/oem.2010.057448]

Knekt, P., Kilkkinen, A., Rissanen, H., et al., 2010. Serum vitamin D and the risk of Parkinson disease. Arch. Neurol., 67(7):808-811. [doi:10.1001/archneurol.2010.120]

Lees, A.J., Hardy, J., Revesz, T., 2009. Parkinson's disease. Lancet, 373(9680):2055-2066. [doi:10.1016/S0140-6736 (09)60492-X]
Li, Y., Wang, C., Zhu, K., et al., 2010. Effects of multivitamin and mineral supplementation on adiposity, energy expenditure and lipid profiles in obese Chinese women. Int. J. Obes., 34(6):1070-1077. [doi:10.1038/ijo.2010.14]

Liu, P., Feng, T., Wang, Y.J., et al., 2011. Clinical heterogeneity in patients with early-stage Parkinson's disease: a cluster analysis. J. Zhejiang Univ.-Sci. B (Biomed. \& Biotechnol.), 12(9):694-703. [doi:10.1631/jzus.B1100069]

Marcinowska-Suchowierska, E., Walicka, M., Talalaj, M., et al., 2010. Vitamin D supplementation in adults-guidelines. Endokrynol. Pol., 61(6):723-729.

Miyake, Y., Tanaka, K., Fukushima, W., et al., 2011. Lack of association of dairy food, calcium, and vitamin D intake with the risk of Parkinson's disease: a case-control study in Japan. Parkinsonism Relat. Disord., 17(2):112-116. [doi:10.1016/j.parkreldis.2010.11.018]

Park, M., Ross, G.W., Petrovitch, H., et al., 2005. Consumption of milk and calcium in midlife and the future risk of Parkinson disease. Neurology, 64(6):1047-1051. [doi:10. 1212/01.WNL.0000154532.98495.BF]

Ross, G.W., Abbott, R.D., Petrovitch, H., et al., 2000. Association of coffee and caffeine intake with the risk of Parkinson disease. JAMA, 283(20):2674-2679. [doi:10.1001/ jama.283.20.2674]

Sehanovic, A., Dostovic, Z., Smajlovic, D., et al., 2011. Quality of life in patients suffering from Parkinson's disease and multiple sclerosis. Med. Arch., 65(5):291-294. [doi:10.5455/medarh.2011.65.291-294]

Speelman, A.D., van de Warrenburg, B.P., van Nimwegen, M., et al., 2011. How might physical activity benefit patients with Parkinson disease? Nat. Rev. Neurol., 7(9):528-534. [doi:10.1038/nrneurol.2011.107]

van den Bos, F., Speelman, A.D., van Nimwegen, M., et al., 2013. Bone mineral density and vitamin D status in Parkinson's disease patients. $J$ Neurol., 260(3):754-760. [doi:10.1007/s00415-012-6697-x]

Voelker, R., 2006. Parkinson disease guidelines aid diagnosis, management. JAMA, 295(18):2126-2128. [doi:10.1001/ jama.295.18.2126]

Xu, Q., Park, Y., Huang, X., et al., 2010. Physical activities and future risk of Parkinson disease. Neurology, 75(4): 341-348. [doi:10.1212/WNL.0b013e3181ea1597]

\section{中文㩯要:}

\section{本文题目：户外活动和维生素 D 的摄入量与帕金森病的风险呈负相关}

Inverse associations of outdoor activity and vitamin $D$ intake with the risk of Parkinson's disease

研究目的：评估户外活动、维生素 $\mathrm{D}$ 的摄入与帕金森病 (PD) 风险关系。

研究方法: 收集 209 例新发 PD 病例和 210 名无神经退行性疾病对照人群, 进行食物频率问卷调查, 计算膳食 维生素 $\mathrm{D}$ 摄入量并记录自我报告的问卷调查户外活动情况。利用多变量 Logistic 回归研究膳食维生 素 $\mathrm{D}$ 摄入及户外活动与 $\mathrm{PD}$ 的相关性, 并校正性别、年龄、吸烟、饮酒、教育程度和身体质量指数 (BMI) 变量。按户外活动时间从少到多四分位分组，校正后的比值比 (OR) (95\%可信区间 (CI) ) 值分别为 1 (参考) 、 $0.739(0.413,1.321) 、 0.501(0.282,0.891)$ 和 $0.437(0.241,0.795)$, 趋 势 $P=0.002$; 按维生素 $\mathrm{D}$ 摄入量从少到多四分位分组, 校正后的 OR 值分别为 1 (参考)、 $0.647(0.357$, $1.170 ） 、 0.571(0.318,1.022)$ 和 $0.538(0.301 ， 0.960)$ ，趋势 $P=0.011$ 。

重要结论: 表明户外活动和总的维生素 D 摄入量与 PD 呈负相关; 户外活动可更显著下降 PD 的风险相关。 关键词组: 户外活动; 维生素 $\mathrm{D}$ 摄入量; 帕金森氏病 